\title{
AOR
}

Selected Papers of \#AolR2019:

The $20^{\text {th }}$ Annual Conference of the Association of Internet Researchers Brisbane, Australia / 2-5 October 2019

\section{CULTURAL COSMOLOGIES OF THE INTERNET: SITUATING DIGITAL NETWORKED TECHNOLOGIES IN DIVERSE MORAL UNIVERSES}

\section{Introductory statement}

This panel explores the ways in which cosmological understandings shape social orientations of trust towards techno-bureaucratic systems. We ask how people negotiate, resist and refuse through the diverse moral universes that arise from the conditions in which people find themselves. The approach we take is informed by scholarship that considers technological practices and how they are embedded in social and cultural cosmologies (Burrell 2012; Horst \& Foster 2018; Miller et. al. 2016). Behavior and choices are guided by moral values that emerge ultimately from a cosmology - a culturally patterned view of the universe and the human place within it (Wilk and Cligett, 2009: 44). The papers in this panel contextualise technological practices that may be considered good, appropriate and right, bad, destructive and malign within moral models of behaviour, articulating tensions of trust.

The first paper in this panel introduces the framework for the moral economy of the mobile phone and emphasises the role of consumers, companies and state agents in resisting and revealing the constraining tendencies of capitalism in Fiji and Papua New Guinea. Horst argues that there are several meanings of free culture associated with digital media and technology which departs from the democratic, liberatory potentials of digital culture. This cosmological diversity highlights mistrust in top-down, hierarchical techno-bureaucratic meanings of sharing information and foregrounds social circulation as an alternative and culturally robust mode of exchange within digital cultures.

In the second paper, Carter explores the good, bad and the ugly of online gaming through examining how players situate their play within the moral economy of the game's socio-technical system. Previous studies have positioned transgressive behaviours such as trolling and cheating as 'within the game' practices. However, the paper highlights how these acts occur within a system of values, influenced by game rules, that determine whether win conditions are established or can be met.

In the third paper, the Spencer draws on an ethnographic study with Australian Indigenous elders and knowledge authorities on digital formats of presenting, recording and archiving research materials. The Spencer argues that these exchanges reveal a

Suggested Citation (APA): Maddox, A., Sinanan, J., Carter, M., Horst, H., Spencer, M., \& Wiesenfeldt, G. (2019, October 2-5). Cultural Cosmologies of the Internet: Situating Digital Networked Technologies in Diverse Moral Universes. Panel presented at AolR 2019: The $20^{\text {th }}$ Annual Conference of the Association of Internet Researchers. Brisbane, Australia: AolR. Retrieved from http://spir.aoir.org. 
set of complex cosmopolitics that support negotiations around inclusion, exclusion and action within shared activities of remaking ancestral and other realities. Yet, she suggests that further attempts for creating transparency emerges from recognising the complexity within these exchanges.

The fourth paper, Sinanan and Wiesenfeldt take a historicized view of how of good and evil, or more specifically the theological understanding of the demonic, are inherent to the navigation of technological systems; and how such culturally shaped cosmologies continue to inhabit contemporary, digital technological systems. Drawing on demonological discourses that frame technologies as inherently evil or as having the capacity to extend the will of human actors, the authors argue that in the cybernetic vision, as in the demonological vision of technology, humans engage in technological systems beyond their control that produces moral ambivalences as to where responsibility, benign or malign intentions lie- within humans or in the machines they produce.

In the final paper, Maddox examines the context collapse between the digital pirate and the digital ethnographer. Through a study of the drug cryptomarket, Silk Road, this paper explores the moral economy of digital pirates in the Dark Web. The quintessential digital culture exemplifying distrust in the system, this community offers more than just an extension of the theory of piracy. They provoke a consideration of the principles of practice.

The unique contribution of this panel is to illustrate the impact of diverse cultural cosmologies upon trust and/or distrust in techno-bureaucratic systems. We move beyond a dualistic frame of life online as either emancipatory or an artefact of engineered domination by 'the system' (Manion \& Goodrum 2000). Instead we seek to reframe social engagement with digital networked technologies through lived experiences in order to encounter diverse world views. It is this cosmological diversity, we argue, that draws us through free cultures, online gaming, indigenous knowledges, a demonic internet and digital pirates. From this arc, we seek to challenge a dominant conceptualisation of a single system and a single view of trust or distrust and nuance the questions surrounding moral cosmologies emerging through socio-technical systems.

\section{References}

Burrell, J., (2012). Invisible Users: Youth in the Internet cafés of urban Ghana. Cambridge MA: MIT Press.

Horst, H. A. and Foster, R.J. (eds), (2018). The Moral Economy of Mobile Phones: Pacific Islands Perspectives. Canberra: ANU Press.

Manion, M., \& Goodrum, A. (2000). Terrorism or civil disobedience: toward a hacktivist ethic. SIGCAS Computers and Society., 30(2), 14-19. doi:10.1145/572230.572232 
Miller, D., Costa, E., Haynes, N., McDonald, T., Nicolescu, R., Sinanan, J., Spyer, J., Wilk, Venkatramen, S. and Wang, X. (2016). How the World Changed Social Media, London: UCL Press.

Wilk, R. R. (2009). Economies and cultures: foundations of economic anthropology: Routledge. 


\section{Paper 1 THE MULTIVALENT MEANINGS OF FREE CULTURE}

Heather Horst

University of Sydney

\section{Introduction}

From organisations such as Creative Commons to figures such as Larry Lessig, free culture represents one of the key ideologies of the digital age. In many parts of the Global South free culture movements are associated with the call for open source software (Horst 2011), the sharing and remixing associated with dancehall, hip hop and other contemporary music and the success of platforms such as FrontlineSMS in Zimbabwe, Nigeria and other parts of Africa. Free culture is associated with a broadening or opening of access to distributing and modifying content, and digital media technologies represent a key mechanism through which these ideals and ideologies operate. Although often framed by legal regimes such as piracy and copyright, free culture-inspired platforms and practices play an important role in the circulation of music, films, videos and other forms of creative culture outside of the global north (Karanovic 2013).

As free culture ideology circulated around the globe so, too, did the liberalization of telecommunications markets in many Pacific Islands countries which led to exponential growth in the distribution and use of mobile phones. In many countries around the world it is the mobile phone, and especially the smartphone, through which free culture is or can be experienced. This paper examines the notions of free culture, and particularly freeness, as they circulate in contemporary studies of digital culture. Drawing upon two research projects based in Fiji and Papua New Guinea, I focus upon the different meanings of freeness operating in Fiji and Papua New Guinea with particular attention to the ways in which 'freeness' has come to garner meaning in people's relationships to telecommunications over the past decade. After introducing the framework of the moral economy of the mobile phone and the role of consumers, companies and state agents in shaping the moral economy (Foster and Horst 2018), I introduce notions of 'freeness' and the culture of 'free' operating in Fiji and PNG. This includes an examination of the ways in which telecommunications companies market and advertise freeness through series of promotions and "deals" designed to incentivize the purchase or use their phones, airtime and data. I then turn to the ways in which mobile consumers themselves create moments of 'freeness' through the use of apps to share music and video made available through the smartphone and associated technologies. By comparing the creation of mobile company's free culture and the emergence of other forms of exchange in everyday consumer use, I highlight the multivalent notions of free culture and what we might think of as a vernacular culture of freeness associated with digital media and technology.

How do we make sense of the vernacular forms of free culture which have emerged and the underlying value of freeness that they reflect and the implications of these for what we might think of as free culture as a concept? How do these different notions of 'free culture' come together, especially given the long history of gifting and exchange, as well as political culture in the Pacific? 
In this paper I argue that there are multiple meanings of free culture operating in Fiji, much of which bears little resemblance to the democratic, liberatory potential of digital culture that celebrated the ability to share and remix various sources of information and creative content. With the forms of freeness now circulating, I suggest that the "free" in "free culture" has been reduced to the possibility and ability to get more than what you pay for and/or avoid paying for minutes, data or content. Certainly this has enhanced, for some, the accessibility to information and the possibilities for sharing and circulating via a variety of networked media (often without and/or circumventing payment), including sites and applications like YouTube, Facebook, WhatsApp and a range of others. Among many people circumventing the use of data either through WiFi or sharing apps such as c-Share where videos and music are quickly and cheaply shared, there is a sense that movies and other works are recognized as part of public culture and are used creatively. Yet, this is about not paying for something of value rather than a recognition of the freedom to distribute and modify creative work.

Elsewhere (Horst 2018) I have argued that mobile telecommunications companies seek to create relationships with people who use mobile services, creating consumer-citizens (building on the work of media scholar Sarah Banet-Weiser and others). Vodafone emphasizes its long-term commitment to Fiji by stressing the citizen dimension of consumer-citizens and Digicel stresses consumers and broader values of global capitalism. The notion of free culture that operates in such contexts - while at times framed by the companies as a gift - is deliberately designed to create a sense of belonging which will in turn obligate consumers to use and keep their services. However, this sense of obligation is transient and must be reframed and reinforced.

The notion of freeness that operates for ordinary (and especially pre-paid) consumers in Fiji and PNG requires knowledge of the broader system, and the capacity to discipline and calculate oneself to take advantage of the forms of freeness being offered. While these practices resonate with the discipline and practice EP Thompson as Foster (2018) has argued in relation to the micro-calculation of little to no data in Papua New Guinea, the ability to leverage freeness operates more like the sense of addiction created in Schull's work on gambling where people become reliant on the system to keep going and use data to continue to remain embedded in the social networks that underpin the mobile network. In effect the free culture that emerges through subversion and gamification by for consumers both subverts and extends the limits of their own capacity to purchase data but it also continues to tie them into the broader system. However, the subversion, and the use of things like WhatsApp and Messenger for talking have impacted the voice call business and have driven the two companies to develop different demands for data. This fundamental tension around the discursive notions of freenees and particular valences of free that circulate between consumers and the companies that operate is part of the moral economy of mobile phones. This tension around who is more or less obligated - and the moments of freeness that emerge - is perhaps a lens through which to understand the ways that digital culture and global capitalism continue to be intertwined.

\section{References}

Foster, R. and Horst, H. (Eds). (2018). The Moral Economy of Mobile Phones: Pacific Perspectives. Canberra: ANU Press. 
Foster, R. (2018). "Top-Up: The Moral Economy of Prepaid Mobile Phone Subscriptions.". In Foster, R and Horst, H. (eds) The Moral Economy of Mobile Phones: Pacific Perspectives. Canberra: ANU Press

Horst, H. (2018). "Creating Consumer-Citizens: Competition, Tradition and the Moral Order of the Mobile Telecommunications Industry in Fiji". In Foster, R. and Horst, H. (eds) The Moral Economy of Mobile Phones: Pacific Perspectives. Canberra: ANU Press.

Horst, H. (2011). Free, Social, and Inclusive: Appropriation and Resistance of New Media Technologies in Brazil. International Journal of Communication, 5: 437-462.

Karanovic, J. (2012). Free Software and the Politics of Sharing. In Horst, H. \& Miller, D. (eds) Digital Anthropology. London: Bloomsbury.

Schull, N. (2012). Addiction by Design: Machine Gambling in Las Vegas. Princeton: Princeton University Press. 


\title{
Paper 2 A CONSTRUCTIONIST APPROACH TO MORAL NORMS IN MULTIPLAYER ONLINE GAMES
}

Marcus Carter

University of Sydney

\begin{abstract}
Research on transgressive and problematic behavior in online gaming environments (eg. cheating, griefing and trolling) has typically conceptualized moral norms and values of videogames as existing within clearly demarcated spheres, albeit spheres that are constantly being negotiated and renegotiated. This process as multiplayer games' demarcation problem (Carter, Gibbs \& Arnold, 2015), draws on Gieryn's theory of boundary-work for understanding the ways acts of play are demarcated as unacceptable (in the form of cheating, or griefing) or acceptable.

Though useful for understanding processes where social rules are established and maintained in multiplayer games, this binary approach inadequately accounts for other practices that are present in, and crucial to the success of, online multiplayer games and how players situate their play within the moral world of the game's socio-technical system. In this paper, I propose a constructionist approach to understanding the moral economy of multiplayer games and present and example from EVE Online that demonstrates its merit.
\end{abstract}

\section{Multiplayer Games as Thought Provinces}

On the concept of scientific disciplines, Clifford Geertz proposed "thinking about thought as a social activity, diversely animated, organized and aimed" (1982, p. 30). Doing so is essentially a means to understand how "separate individuals come to conceive, or do not, reasonably similarly similar things" (p. 23). This, he argues, overcomes the error that lies "in attempting to interpret cultural materials as though they were individual expressions rather than social institutions" (1982, p. 16). This way of conceptualizing disciplinary thought - as a key example of a thought province - can be an extremely useful lens for understanding forms of negotiation, resistance and refusal that occur around player perceptions of a game's rules and moral norms.

Drawing on this approach, I argue, is to recognize that all acts that occur within a multiplayer game are held within a system of values, a game's moral economy (Carter, 2018). Valuing certain play acts, styles, strategies and events over other instances of play is intrinsic to the function of multiplayer games It is through valuing play that win conditions are established or can be met; e.g. Paper beats rock. The most common way in which value is influenced is through rules.

Rules are also extremely influential in devaluing play, principally through categorising them as being against the rules, with some form of penalty. While picking up the ball and running it through the opponent's goal posts in a Roman-legion Testudo formation might successfully move the ball between the goal posts, rules against using your hands to touch the ball devalue it. Rudimentary stuff - rules are at the forefront of the 
practice of valuing play and have consequently been given primacy in definitions of, and attempts to understand, games and game play (Stenros, 2017).

However, rules are not the only mechanism with which play is valued in multiplayer games. Prior work has shown how terms and concepts like sportsmanship (Moeller, Esplin \& Conway, 2009), cheating (Consalvo, 2007), fair-play (Butcher \& Schneider, 1998), griefing and trolling (Lin \& Sun 2005) are attached to play acts, events and strategies to change their worth, irrespective of their relation to rules. Game paratexts (Genette, 1991; 1997) help "structure [play] and give it meaning" (2007, p.21), and that they play a key role in telling a player "how to play, what to play, and what is cool (and not) in the game world" (p.22). A game's imaginary, its fictive world also serves a similar role in shaping how play is valued.

In the mutual, shared recognition of this moral economy, multiplayer games can be considered a form of Geertz's thought province; a socially constructed system about which players collectively conceive reasonably similar values. Such an approach decentralizes written rules in how we might examine the social codes of online worlds and prioritizes attention to the sociality of their existence.

\section{Case Study: Killing on Sight in Dayz}

DayZ is a survival, sandbox first-person shooter games in which players scavenge items to survive in a zombie apocalypse. Featuring high-consequence death that encourages players to avoid conflict (Carter, Gibbs \& Wadley, 2013), yet ultimately configured as a combat simulator, the online community of DayZ players constantly negotiates the tension between survival and killing. One such site of negotiation is the practice of 'Killing on Sight' (KoS), where players are immediately (and always) hostile towards other players they encounter.

KoS is an excellent example of a type of play overlooked by a binary approach to understanding transgressive play in online game environments. It is within any coded and formal rules of the game, but has the capacity to negatively - and significantly impact the play of others, and is subsequently widely condemned and denigrated by players as "unsportsmanlike", "despicable" and "scummy". The lack of these formal rules make DayZ a fruitful site of investigation, since it uncovers the socio-technical systems at work in establishing a game's moral economy.

A constructionist approach to understanding this form of play, that crucially exists within the moral economy of DayZ does not offer the opportunity to identify if this is indeed a "piece of shit" thing to do, but rather, identifies the sites and processes that shape the production and experience of the DayZ gameworld. It highlights the role that online spaces - such as reddit gaming forums and YouTube - play in devaluing KoS behavior (via memes and stories) and valuing other, more social ways of playing.

Participant responses to a $1700+$ player motivations survey further identified other factors that players draw on to understand how to play, and how to respond to the play of others (Carter and Allison, 2018). Many drew on the game's zombie-apocalypse imaginary, complaining about KoS players, "I don't think people would act like that in the 
apocalypse". Another the configuration of high consequence death, "the point of permadeath is to discourage KoS", unveiling the primacy of the designer's intent. More though, even in this post-apocalyptic combat simulator where death is necessary for the desired intense experience of play, situated their complaint within the mutual desire for everyone to have pleasurable experience. These social, technological and immaterial systems collide to shape the experience and social activity of playing DayZ.

\section{References}

Butcher, R., \& Schneider, A. (1998). Fair play as respect for the game. Journal of the Philosophy of Sport, 25, 1-22.

Brown, A. (2012). "No one-handed typing": An exploration of gameness, rules and spoilsports in an erotic role play community in world of warcraft. Journal of Gaming \& Virtual Worlds, 4, 259-273.

Carter, M., Gibbs, M. \& Wadley, G. (2013) “Friendly, Don't Shoot!": How Communication Design can Enable Novel Social Interactions. In Proceedings of the $24^{\text {th }}$ Australian Computer-Human Interaction Conference (ozCHI'12), ACM Press, p. 72-75.

Carter, M., Gibbs, M., \& Arnold, M. (2015). The demarcation problem in multiplayer games: Boundary-work in EVE online's eSport. Game Studies, 15. Retrieved from http://gamestudies.org/1501/articles/carter

Carter, M. (2017). Valuing Play in Survivor. Games and Culture. (Online First)

Carter, M. \& Allison, F. (2018). Guilt in DayZ. In K. Jorgensen and F. Karlsen's Transgression in Games and Play. Cambridge, MA.: MIT Press.

Consalvo, M. (2007). Cheating. Cambridge, MA.: MIT Press.

Geertz, C. (1982). The way we think now: Toward an ethnography of modern thought. Bulletin of the American Academy of Arts and Sciences, 35, 14-34.

Genette, G. (1991). Introduction to the paratext. New Literary History, 22, 261-272.

Genette, G. (1997). Paratexts: Thresholds of Interpretation. London, England: Cambridge University Press.

Gieryn, T. F. (1983). Boundary-work and the demarcation of science from non-science. American Sociological Review, 48, 781-795.

Gieryn, T. F. (1999). Cultural boundaries of science: Credibility on the line. Chicago, IL: The University of Chicago Press.

Lin, H., \& Sun, C. T. (2007). "White-eyed" and "Griefer" player culture: Deviance construction in MMORPGs. In S. de Castelle \& J. Jenson (Eds.), Worlds in play: 
International perspectives on digital games research (pp. 103-114). New York, NY: Peter Lang.

Moeller, R., Esplin, B., \& Conway, S. (2009). Cheesers, pullers and glitchers: The rhetoric of sportsmanship and the discourse of online sports games. Game Studies, 9. Retrieved from http://gamestudies.org/0902/articles/moeller esplin conway

Stenros, J. (2017). The game definition game. Games and Culture, 12, 499-520. 


\section{Paper 3 DIGITAL FIRST: BEING SENSITIVE TO EPISTEMIC POLITICS}

Michaela Spencer

Charles Darwin University

\section{Abstract}

'Digital First' is an emerging paradigm in the College of Indigenous Futures, Arts and Society at Charles Darwin University (CIFAS 2019), where Indigenous teachers and learners comprise a growing proportion of the university and there are strong connections between the university and both urban and remote Aboriginal communities.

This paradigm is coming to infuse both teaching and research within many areas of the university, and offers both challenges and opportunities to research and teaching staff. As a member of a small 'Ground Up' team of researchers and educators who work collaboratively with Indigenous elders and knowledge authorities as well as government and non-government organisations, this transition carries implications for our ongoing research collaborations and everyday practices (www.groundup.cdu.edu.au).

As a researcher and educator facilitating gradual transitions to 'Digital First' ways of working, I am involved in developing online profiles and e-portfolios for researchers showcasing their professional skills, exploring digital formats for presenting, recording and archiving research materials, and developing micro-credentials which can recognise community-based research skills exhibited by Indigenous and other researchers. Supporting connections between research and learning, also involves reshaping online course materials so as to support community-based learners, and developing forms of practically based research training and assessment suitable for students operating in Aboriginal languages and prioritizing oral and visual forms of presentation.

The first part of the paper takes the embodied work of crafting these new practices and technologies as a site of research, and offers several ethnographic episodes arising within this research and teaching work. These episodes emerge at the intersection of community-based research and learning practices, and new forms of 'Digital First' technologies and ways of operating where surprises and challenging demands often arise. For example, requests to accommodate group enrolment and learning within course structures as community-based researchers push to enroll in research diploma courses in groups which encompass senior and junior learners; grandmothers and grandchildren. The apparent necessity of developing ways of accounting student/researcher identities as relationally configured in place, rather than appearing independently from the outside. And, the conceptual hijinks required when developing online research resources and findings that are explicit about their performative capacities in use.

The second part looks to juxtapose these ethnographic accounts with work produced by an earlier generation of Ground Up researchers exploring possibilities of online learning and digitally mediated knowledge work. In the early 2000's a number of initiatives were established by groups of CDU based researchers, and Yolnu colleagues and 
collaborators in East Arnhem Land. The program Teaching from Country established processes for conducting online distance education in reverse, with Yolnu lecturers teaching from remote places, to students in urban centres (http://learnline.cdu.edu.au/inc/tfc/). While the program 'Indigenous Knowledge and Resource Management in Northern Australia (IKRNMA): Making collective memory from computers' explored tools for capturing, storing and using digital objects concerning collective life and place. Writing about these efforts, Verran and Christie (2007) described the work of Yolngu elders struggling against the grain of digital technologies designed to represent, to use them in ways that were actively performative in expressing the remaking of an ancestral reality. At the same time, exploiting the possibilities the technologies offered for representation in achieving political ends in dealing with representatives of mainstream Australia (2007: 214).

My suggestion is that juxtaposing these sets of research materials allows each to be read as enacting a relational ethics of Digital First; that is, to enact a working 'cosmopolitics'. Cosmopolitics is a term that was first coined by Isabelle Stengers' to denote an on-going exploration of who or what may participate in the composition of a shared world, and how (Stengers 2005). In their recent book, Mario Blaser and Marisol de la Cadena pick up on this term, and the associated concept of 'political ontology', to foreground the need for a minimalist translating frame when considering performative practices capable of working multiple worlds. They suggest other interpretive options such as '... political economy and political ecology, formulated with ideas of nature and economic growth, are insufficient (at times even unable) to think antagonisms that, for example, involve things like mountains and forests that emerge as resources through some practices but also as persons through other practices' (2018: 5, see also Blaser 2009).

As such, cosmopolitics denotes a politics across worlds that lacks - or even more strongly, denies the necessity of - a common ground as a precursor to performative action (Dányi \& Spencer 2019). Looking back to the archive examples of online learning and tools for managing digital objects helps to make visible ways of working technologies as social and material assemblages, and to reveal a relational ethic of digital design. This relational ethic remains significant as arrangements of Digital First university curricula and assemblages come to life. Learning to work such an ethics carefully and well may be an important step for the novice Digital First cosmopolitician seeking to participate in new forms of digital design and pedagogy.

\section{References:}

College of Indigenous Futures, Arts and Society (2019) Strategic Plan. Internal document.

de la Cadena, M., \& Blaser, M. (Eds.). (2018). A world of many worlds. Duke University Press.

Dányi, E. \& Spencer, M. (2019). Un/common grounds: Tracing politics across worlds, Social Studies of Science. Forthcoming. 
Stengers, I. (2005). The cosmopolitical proposal. Making things public: Atmospheres of democracy, 994, 994.

Verran, H., \& Christie, M. (2007). Using/Designing Digital Technologies of Representation in Aboriginal Australian Knowledge Practices. Human Technology: An interdisciplinary journal on humans in ICT environments. 


\title{
Paper 4 SORCERER'S APPRENTICE OR MANICHAEAN DEVIL? A DEMONOLOGICAL UNDERSTANDING OF TECHNOLOGICAL SYSTEMS AND DIGITAL MEDIA
}

\author{
Jolynna Sinanan \\ University of Sydney \\ Gerhard Wiesenfeldt \\ University of Melbourne
}

\begin{abstract}
A widespread argument declares technological systems as purely physical and thus value neutral (Pitt, 1999). Against this idea, approaches in science and technology studies have pointed out the inherent normative constructions along inclusionary and exclusionary frameworks (Winner, 1980; Radder, 2009), thus emphasizing the social nature of technology. With the swift uptake of digital and mobile media and the even faster integration of these technologies into everyday routines and practices, good and evil, or emancipatory and dominating potentials become invisible or obscured. Miller and Horst suggest that a consequence of technologies becoming rapidly mundane is that what is experienced is not necessarily the technology, but an 'immediately cultural inflected genre of usage' (2010: 29). Issues of blame and morality that are inextricable from cultural understandings are often projected onto technologies themselves.

In this paper, we take a step further and present a historicized view of the ways in which good and evil, or more specifically, demonic understandings are inherent to the navigation of technological systems and that such culturally shaped cosmologies continue to inhabit contemporary, digital technological systems. Technology is thus less in the realm of the natural or the social, but belongs to the preternatural. Our approach is similar to Canales' and Krajewski's (2012) historical epistemology of scientific demons and resonates with Kelty's observation that data, algorithms and infrastructure can embed forms of exclusion and domination through their implementation by social actors in their everyday operation, but the kinds of evil in question simply goes unmeasured, or remains hidden (2017). By revisiting the explicit notion of evil as demonic, we argue that such qualities are important to recognize if we are to appreciate and more fully understand the role of consequences of digital media in everyday life. Reflecting on the ubiquity of mobile phones in the first ten years or so, Arnold draws on the mythical Janus face as a metaphor to examine how mobile phones have both benign and malign potentials at the same time (2003). We take this idea further as digital media produces relationships that extend far beyond dyadic communication between individuals and employ the notion of the demonic to reconsider the moral norms of social and material infrastructures. We are interested in how far the ontologies of technologies contain the concepts of demons, in a theological rather than an epistemological interpretation of technology.
\end{abstract}

\section{The demonic nature of technology}


The theological discussion of technology as a matter of good or evil was framed by the Manichaean challenge to early Christianity, which classified material technology as belonging to the realm of Darkness and thus inherently evil (Coyel, 2009). Rejecting the idea of a second, dark creation, Augustinian theology reconceptualized evil as a deviant form of good - a privation of form and substance (Mathewes, 2001). In early modern demonology, this notion led to an understanding of technology as natural magic that was necessarily either good or evil. Natural magic was the human activity of engaging preternatural demons as active agents that change the natural course of things (Clark, 1999). While invoked demons could be good or evil, their actions were intrinsically beyond human control and their true nature often hidden from humans. In the demonological discourse, the conditions under which demons could ethically be invoked remained contested, but a key criterion related to the mastery of the magus who possessed the required knowledge and experience to perform magic responsibly. The literary figure of the sorcerer's apprentice and of Faust established the risks that demonic practices could face from either ignorance or intellectual vanity (Tambling, 2016). On the other hand, the figure of the witch embodied black magically practices that invoked demons to exercise invisible control over other people to their detriment (Brock et al. 2018).

While modern techno-science was established - at least rhetorically - by rejecting the old demonological ideas and thus understanding technological knowledge as inherently beneficial to humanity (D'Alembert, 2000), the moral ambivalence of technology remained. The ambivalence was not only about the excesses of technological progress - the 'dark satanic mills' of the industrial revolution - but also about inventions such as Humphry Davy's safety lamp that were intended as purely beneficial, yet resulted in negative consequences; in Davy's case the intended use to save miners' lives enabled practices that increased the death toll (Golinski, 2016). The demons of technological systems proved to be beyond the scientist's control. Consequently, demons reentered the scientific imaginary in the works of Laplace, Maxwell and others as superhuman beings with the mastery to control the very phenomena out of reach of humans (Weinert, 2016; Osietzki, 2001). The involvement of techno-science in modern warfare provided moral dilemmas, culminating in the 'evil technology' of toxic gases in World War I, causing invisible harm and death to soldiers (Friedrich et al., 2017). The demonic ontology of technology became central to Norbert Wiener's conceptualization of cybernetic warfare as a fight against a Manichaean devil that used disguise and dissimulation and needed to be emulated in order to be defeated (Galison, 1994).

More recently, the notion of the demonic as human-technological deviant has been employed by internet and communication scholars to counter the anxieties produced by the increased ubiquity of algorithms, data flows and automation in everyday life. Fuller and Goffey consider digital platforms 'evil' in their ability to have an active capacity to shape and manipulate things and people that come into contact with them (2012). McKelvey quite directly uses demons to interpret 'daemons' as potentially mischievous software for distributed and dynamic social control (2018).

In the cybernetic vision as in the demonological vision of technology, we engage in technological systems beyond our control producing moral dilemmas stemming from our inability to clearly discern good and evil demons, while maintaining the same criteria for 
evils in technology - the invisible control and the irresponsible transgression of our expertise. Our trust in technological systems we engage with, but don't control, is the trust in a benevolent demon.

\section{References}

Arnold, M., (2003). On the phenomenology of technology: the "Janus-faces" of mobile phones. Information and Organization, 13(4), pp.231-256.

Brock, M. D. et al. (2018). Knowing Demons, Knowing Spirits in the Early Modern Period. London: Palgrave Macmillan.

Canales, J., Krajewski, M. (2012). Little Helpers. About demons, angels and other servants. Interdisciplinary Science Reviews, 37(4), 314-331.

Clark, S. (1999). Thinking with Demons: The Idea of Witchcraft in Early Modern Europe. Oxford: Oxford University Press.

Coyel, J. K. (2009). Manichaeism and Its Legacy, Boston: Brill.

D’Alembert, J. L.R. (2000). “Discours préliminaire de l'Encyclopédie”, Paris: Vrin.

Friedrich, B., et al. (2017). One Hundred Years of Chemical Warfare: Research, Deployment, Consequences. Berlin: Springer.

Fuller, M. and Goffey, A., (2012). Evil Media. Cambridge: MIT Press

Galison, P. (1994). The ontology of the enemy: Norbert Wiener and the cybernetic vision", Critical Inquiry 21(1), 228-266.

Golinski, J. (2016). The Experimental Self: Humphry Davy and the Making of a Man of Science. Chicago: The University of Chicago Press.

Horst, H. A., \& Miller, D. (Eds.). (2013). Digital Anthropology. London: Bloomsbury.

Kelty, C. (2017). "Introduction: Evil Infrastructures." Theorizing the Contemporary, Cultural Anthropology website, April 28. https://culanth.org/fieldsights/1106-introductionevil-infrastructures.

Mathewes, C. T. (2001). Evil and the Augustinian Tradition. Cambridge: Cambridge University Press.

McKelvey, F. (2018). Internet Daemons: Digital communications possessed. Minneapolis. University of Minnesota Press.

Osietzki, M. (2001). 'Dämon' gegen 'Wärmetod': Energie und Information in der männlichen Naturaneignung des 19. und 20. Jahrhunderts, Freiburger FrauenStudien, 11, 89-112. 
Pitt, J. C. (1999). Thinking About Technology: Foundations of the Philosophy of Technology. New York: Seven Bridges Press.

Radder, H. (2009). "Why Technologies Are Inherently Normative", in Meijers, A., Philosophy of Technology and Engineering Sciences, Amsterdam: North-Holland, 887921.

Tambling, J. (2016). Histories of the Devil: From Marlowe to Mann and the Manichees, London: Palgrave Macmillan.

Weinert, F. (2016). The Demons of Science: What the Can and Can't Tell Us about Our World, Cham: Springer.

Winner, L. (1980). Do artifacts have politics?. Daedalus, 109(1), 121-136. 


\section{Paper 5 RESEARCHING DIGITAL PIRATES IN THE DARK WEB: AN ETHNOGRAPHIC REFLECTION}

Alexia Maddox
Deakin University

Abstract

Media reports sensationalise the Dark Web as a seedy digital location where drugs, guns, hitmen and child pornography circulate through eBay-style marketplaces that are only accessible to your hacker types. Here, elusive fringe behaviours proliferate in plain sight, with identities hidden through encryption technologies and secretive user cultures. In 2013, I began collaborating on a digital ethnography of the most popular Dark Web drug market, Silk Road. The social impacts of an online drug market defined by choicedriven drug purchasing, highly visible yet anonymous user cultures and customer-tocustomer $(\mathrm{C} 2 \mathrm{C})$ drug sales were unknown. This paper is a contemplation of ethnographic research practice with the online community surrounding Silk Road, the first widely used cryptomarket for drugs on the Dark Web. To position the study within a cosmological moral universe, a theory of piracy is interrogated for its explanatory capacity of the digital pirates of the Dark Web. As has been previously argued (Dawdy and Bonni 2012; Johns 2010), there are significant continuities between the pirates of the open seas and the pirates of digital spaces.

Cryptomarkets are e-commerce websites that operate in the Dark Web, commonly referred to as darknet markets (DNMs). The Dark Web (or darknet) is an overlay of special routing software designed to provide anonymity for website visitors and publishers (Gehl, 2018). In this paper, I socially finese the definition of cryptomarkets to argue that they are a domain of activity for marginalised populations who prefer eBay style drug access (referred to here as 'choice-driven' access) and a preference towards information liberty and self-sovereignty. As the ethnographer on the ground, my aim for entering the Silk Road cryptomarket was initially to immerse with the microcosm of a digital culture forming and reforming in the Dark Web.

There is an emerging field of scholarship into cryptomarkets that draws together criminologists, media scholars, sociologists, and computer scientists (cf. Barratt and Aldrige 2016). However there remains a disconnect between existing literature engaging with the cryptomarket space and relevant anthropological scholarship that may illuminate its social adoption, user cultures and the meaning making that arises through the social appropriation of technological innovations. To address this gap, I will connect this research to anthropological literature on illegal practices (Thomas and Galemba 2013, Roitman 2006) such as drug use and distribution (Polson 2013) and piracy (cf. Dent 2012). I will also draw in literature on platform affordances (Nardi 2015) specific to hacker cultures (cf. Coleman and Golub 2008, Coleman 2014), and online visibility, especially in the negative/dark sense such as trolling (Philips 2015) as a way to frame cryptomarkets and their surrounding users and communities. 
In contrast to the illegal yet socially licit blackmarket described by Roitman (2006) in the Chad Basin, the moral economy surrounding the Silk Road cryptomarket etched out a space of independent economy, collaborative creativity and political resistance. The cryptomarket encoded Johns (2009)' notion that digital pirates undermine property and enact security through technical designs that avoid centralised control and harness peer-to-peer architectures. The justification for the retail of illicit commodities rested on anarchist values of formative internet cultures (Levy 1984) that argue for user privacy and the free circulation of information (and drugs). We can connect these observations to define Silk Road as an autonomous pirate state in the Dark Web that was operating on decentralised and securitised principals of trade. The early work of Barratt (2012) describes the peer-to-peer architecture of Silk Road as producing an eBay for drugs and the central role of encryption and cryptocurrencies for decentralised exchange and privacy practices (Gehl 2018; Nelms et al. 2018). Because of the site founder and initial core member's orientation towards information liberty, anonymity and personal privacy linked to notions of self-sovereignty, they initiated a secure platform and marketplace based upon anonymising technologies that bootstrapped cryptocurrencies and started a whole wave of innovation.

In review, the start of the study unexpectedly coincided with the FBI seizure of Silk Road in October 2013. The field site disappearance provoked a practice-based and conceptual rewiring. For example, in the paper I unpack how the 'hydra effect' introduced to conceptualise resilient innovation within cryptomarkets can also apply to research practice. Consequently, throughout this paper I argue that there is a predictable and yet uncanny parallel between field site and research practice. To illustrate this, I further explore how practices that characterise cryptomarkets, such as contention, disruption, redirection, obsolescence, construction and iteration, are paralleled within digital ethnographic practice. I would argue however that this reflexive knowledge is not sufficient and must be accompanied by the researcher's own vulnerability, a common element of being human. Perhaps, on the high seas of the Dark Web, it is through vulnerability that there can be a context collapse between the digital ethnographer and the digital pirate.

\section{References}

Barratt, M. J. (2012). "Silk Road: eBay for drugs." Addiction 107 (3):683-683, https://doi.org/10.1111/j.1360-0443.2011.03709.x

Barratt, M. J., and J. Aldridge. 2016. "Everything you always wanted to know about drug cryptomarkets* ("but were afraid to ask)." International Journal of Drug Policy 35:1-6. doi: 10.1016/j.drugpo.2016.07.005.

Coleman, E. G. and Golub, A. (2008). "Hacker practice: Moral genres and the cultural articulation of liberalism." Anthropological Theory, 8(3), 255-277.

https://doi.org/10.1177/1463499608093814

Coleman, G. (2014). Hacker, hoaxer, whistleblower, spy: The many faces of Anonymous. London : New York : Verso Books 
Dawdy, S. L., \& Bonni, J. (2012). Towards a General Theory of Piracy. (3), 673. doi:10.1353/anq.2012.0043

Dent, A. S. (2012). Understanding the War on Piracy, Or Why We Need More Anthropology of Pirates. Anthropological Quarterly, (3), 659.

Gehl, R. W. (2018). Weaving the Dark Web : legitimacy on freenet, Tor, and I2P. Cambridge, MA : The MIT Press

Johns, A. (2009). "Piracy as a Business Force." Culture Machine 10:44-63.

Johns, A. (2010). Piracy: The Intellectual Property Wars from Gutenberg to Gates. Chicago: University of Chicago Press.

Levy, S. (1984). Hackers: Heroes of the computer revolution. Garden City, N.Y. : Anchor Press/ Doubleday.

Martin, J. A. (2014. "Lost on the Silk Road: Online drug distribution and the 'cryptomarket'." Criminology and Criminal Justice 14 (3):351-367. doi:10.1177/1748895813505234.

Nardi, B. (2015). "Virtuality." Annual Review of Anthropology, 44, 15-31. doi:10.1146/annurev-anthro-102214-014226

Nelms, T. C., B. Maurer, L. Swartz, and S. Mainwaring. (2018). "Social Payments: Innovation, Trust, Bitcoin, and the Sharing Economy." Theory, Culture and Society, 35(3), 13-33. https://doi.org/10.1177/0263276417746466

Phillips, W. (2015). This is why we can't have nice things : mapping the relationship between online trolling and mainstream culture. Cambridge, Massachusetts ; London, England: The MIT Press.

Polson, M. (2013). Land and Law in Marijuana Country: Clean Capital, Dirty Money, and the Drug War's Rentier Nexus. Political and legal anthropology review : PoLAR, 36(2), 215-230. doi:10.1111/plar.12023

Roitman, J. (2007). The Right to Tax: Economic Citizenship in the Chad Basin. Citizenship Studies, 11(2), 187-209. doi:10.1080/13621020701262636

Thomas, K., \& Galemba, R. B. (2013). Illegal Anthropology: An Introduction. PoLAR: The Political and Legal Anthropology Review, 36(2), 211-214. 